\title{
FLOW INJECTION ANALYSIS WITH TENSAMMETRIC DETECTION FOR THE DETERMINATION OF DETERGENTS
}

\author{
M. BOS, J. H. H. G. VAN WILLIGEN and W. E. VAN DER LINDEN* \\ Department of Chemical Technology, Twente University of Technology, P.O. Box 217, \\ 7500 AE Enschede (The Netherlands)
}

(Received 19th August 1983)

\section{SUMMARY}

A straightforward flow injection method for the tensammetric determination of surfactants is described. The flow-through cell is equipped with a mercury-coated gold electrode as the working electrode. Ionic as well as nonionic surfactants can be determined in the concentration range $10^{-5}-10^{-4} \mathrm{M}$. The calibration graph is not linear but with an approximation by a polynomial or a cubic spline function, correct results can be obtained with an accuracy of $\pm 4 \%$. The sample rate is about $60 \mathrm{~h}^{-1}$.

The determination of surfactants in aqueous solutions is of great importance both in production control and in the monitoring of, for example, sewage water. There are two types of standard method, both based on ionpair extraction [1]. Probably the most widely used is the two-phase titration procedure; the other type comprises direct photometric determinations in the organic phase. Because these methods are rather time-consuming, much attention has been given to the development of other methods during the last decade. The most important contributions are in the field of potentiometry, particularly with ion-selective electrodes [2-9], and tensammetry [10-15]. Recently, also automation of existing extraction procedures and subsequent photometric detection has been pursued. These attempts are either based on the continuous flow technique (AutoAnalyzer system) $[16,17]$ or on flow injection analysis $[18,19]$. The elegant phase separation by means of a permeable membrane used by Kawase and coworkers is worth mentioning. Such a phase separator will be superfluous, however, with flowthrough detectors based on potentiometry or tensammetry. Because the potentials of surfactant-sensitive electrodes are, in general, not very stable and reproducible, these electrodes are mostly used for end-point indication in titrations; they are not suitable for flow-through detectors.

Detectors based on the tensammetric principle seem to be more promising in this respect. Such a flow-through detector, based on a dropping mercury electrode, has been described for applications in h.p.l.c. [14]. Although it offers the advantage of a clean surface every few seconds, it has the disadvantage that its proper functioning is sensitive to changes in flow conditions. 
The use of a solid electrode not only simplifies the cell construction, but makes the whole system more robust and allows larger variations in the flow rate. Because the object of the present work was the development of a fast procedure for the direct determination of detergents, flow injection in conjunction with tensammetric detection at a solid electrode seemed to be an obvious choice. The feasibility of such a system is assessed here.

\section{THEORY}

In tensammetry the capacitance of the electrical double layer of an electrode is measured. The value of this capacitance is strongly influenced by the presence of adsorbing species. In the equilibrium state strongly adsorbing compounds present in sufficiently large concentration tend to cover the surface totally, yielding a constant capacitance value. At lower concentrations the coverage will follow the adsorption isotherm provided that equilibrium between surface and bulk concentration is attained. This equilibrium may not be reached at a relatively fast dropping mercury electrode because the expansion of the surface exceeds the supply of adsorbate from the bulk. Under such circumstances the coverage, and so the actual capacitance value measured, will be controlled by mass transport. This means that for normal polarographic conditions, where mass transport is caused by diffusion only, a linear relationship between capacitance and concentration can be expected $[20,21]$.

In a flow-through cell with a stationary electrode, no extra transport caused by surface expansion is needed. Convection will assist the pure diffusion process in achieving an equilibrium state between surface and bulk concentration. Therefore, it can be expected that in a flow-through cell with stationary electrode, the capacitance vs. concentration graph will more or less follow the adsorption isotherm, which generally is not linear. To cope with such calibration curves, polynomial functions are often used and cubic spline functions have been suggested [22]. For a polynomial function, the constants are obtained by least-square fitting whereas the degree of the polynomial is determined by trial $[23,24]$. A drawback of this approach is that, especially with polynomials of higher degree, there is no guarantee that the curve will be smooth and without oscillations between the calibration points. The use of cubic spline functions can help to circumvent this problem [25], and does not seem to have been used previously for calibration purposes.

\section{EXPERIMENTAL}

\section{Chemicals}

Sodium dodecylsulphate (puriss.), diisobutylphenoxyethoxyethyldimethylbenzylammonium chloride monohydrate (Hyamine 1622), hexadecylpyridinium chloride (purum), diisobutylcresoxyethoxyethyldimethylbenzylammonium chloride monohydrate (Hyamine 10X), benzalkonium chloride 
(purum), hexadecyltrimethylammonium bromide (purum) were from Fluka. Sodium sulphate (zur. Anal.) and dioctyl sodium sulphosuccinate were from Merck. All were used as received. Solutions were prepared with deionized water that was filtered through Millipore Q2 filters.

\section{Equipment}

A schematic diagram of the flow injection equipment is shown in Fig. 1. A peristaltic pump (Gilson, Minipuls 2), was used to produce a flow rate of $1.25 \mathrm{ml} \mathrm{min}{ }^{-1}$ in each channel. Samples were introduced with a Rheodyne manual injection valve equipped with a 60- $\mu 1$ sample loop. Teflon tubing (0.8 mm i.d.) was used to connect the voltammetric cell (Metrohm EA-1096) with the pump and the injection valve. To avoid trapping air bubbles, the cell was placed with its outlet tubing pointing vertical and upwards.

The working electrode was a gold electrode $(5 \mathrm{~mm}$ diameter; Metrohm EA-286/3) which has been covered by mercury by dipping it in polarographic-grade mercury and wiping off adhering mercury drops. The smooth mercury surface thus obtained could be used for at least a week without renewal. The reference electrode was a silver/silver chloride electrode filled with $3 \mathrm{M} \mathrm{KCl}$ (Metrohm EA-442). An uncoated gold electrode (Metrohm EA-286/3) was used as counter electrode.

The equipment for operating the voltammetric cell as a tensammetric detector consisted of a PAR polarograph, model 174, together with its AC interface and a PAR lock-in amplifier, model 122. The phase angle used was $90^{\circ}$. A Philips PM- 8100 chart recorder was used. The measuring system was calibrated in capacitance units with the use of a dummy cell constructed with a standard capacitance decade. The supporting electrolyte was $0.1 \mathrm{M}$ $\mathrm{Na}_{2} \mathrm{SO}_{4}$ in all experiments.

\section{RESULTS AND DISCUSSION}

Although tensammetry is possible at all kinds of electrode surfaces, mercury is the most widely used electrode material and was therefore selected for these experiments. The major problem in preparing a stationary working electrode for tensammetric measurements is the formation of a homogeneous and well-defined surface. In this respect, the mercury film on a gold support obtained by simply dipping in mercury was much easier to prepare and showed a more favourable behaviour than electrochemically deposited mercury films on glassy carbon or carbon paste.

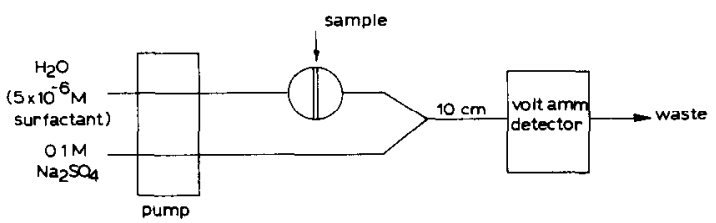

Fig. 1. Schematic diagram of the flow injection equipment for the determination of detergents. 
In the present flow injection determinations, all measurements were made at a d.c. potential of $-0.85 \mathrm{~V}$ vs. $\mathrm{Ag} / \mathrm{AgCl}(3 \mathrm{M} \mathrm{KCl})$ except for the benzalkonium chloride which was measured at $-0.40 \mathrm{~V}$. These potentials were chosen in between the two adsorption/desorption peaks where a decrease of the capacitance is generally observed in the presence of specifically adsorbing species.

For some of the surfactants examined, the flow injection peaks (capacitance vs. time curves) had the normal, slightly asymmetric shape; for some others, however, enhanced tailing seemed to occur after the signal had returned to a certain level above the baseline. Nevertheless, the same peak maxima were reached for subsequent injections at various intervals even though the surface was apparently still covered by small, but varying amounts of surfactant molecules from previous injections. This indicates that it is the absolute value of the maximum capacitance that is of importance. It is more attractive, however, to have a steady baseline, thus a small amount of surfactant was added to the carrier stream to make its concentration approximately $5 \times 10^{-6} \mathrm{~mol}^{-1}$. An additional advantage of maintaining a small concentration of surfactant in the carrier stream is that active sites in the system between injection and detection remain blocked throughout the whole procedure. A similar procedure has been recommended before for potentiometric flowthrough detectors $[26]$.

For various detergents (anionic, cationic and nonionic), standard solutions were prepared, generally in the range $10^{-5}-10^{-4} \mathrm{~mol} \mathrm{l}^{-1}$. From each stock solution, diluted standards were prepared with concentrations in the ratio $1: 2: 3: 6: 8: 10$. Because the calibration graphs were not linear, the "best" curve had to be calculated. Two procedures were adopted: (i) a polynomial fitting procedure, (ii) a cubic spline approximation with 3 intervals. If the total concentration span of the calibration graph is equal to $C_{\text {tot }}$, the intervals chosen are: $0.1 C_{\text {tot }}-0.3 C_{\text {tot }}, 0.3 C_{\text {tot }}-0.6 C_{\text {tot }}$ and $0.6 C_{\text {tot }}-1.0 C_{\text {tot }}$. This number of intervals is the maximum that still produces a unique set of cubic splines describing the data with six distinct concentration values. Each calibration solution was measured four times and the complete data set was used in the calculations. The computer programs for the calculations were written in FORTRAN and are based on the corresponding subroutines from the NAG library [24].

A typical cubic spline calibration graph is presented in Fig. 2. The scale of the drawing is too small to show the difference between the polynomial and the cubic spline functions fitting the data, therefore only the spline function is plotted. However, the numerical values for this calibration show that the cubic spline approximation follows the data more closely in the lower concentration range (Table 1 ).

Test samples were prepared independently for all surfactants. For each sample the average of four measurements was used for calculation of the concentration. The results are presented in Table 2. Because the concentrations of the test solutions were chosen in the middle of the calibration range, 


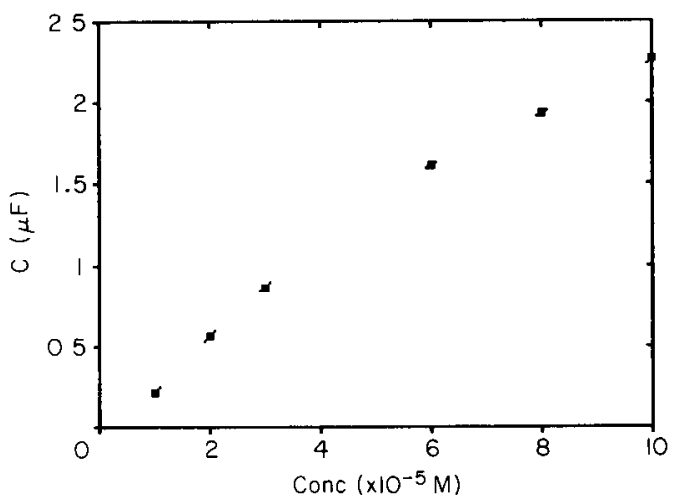

Fig. 2. Calibration plot for Hyamine 1622: (․) cubic spline approximation; ( $)$ experimental points averaged over 4 measurements.

TABLE 1

Calibration data for Hyamine 1622

\begin{tabular}{|c|c|c|c|c|c|c|c|}
\hline \multirow{2}{*}{$\begin{array}{l}\text { Conc. } \\
\left(\times 10^{-5} \mathrm{M}\right)\end{array}$} & \multicolumn{4}{|c|}{$\begin{array}{l}\Delta C \text { measured } \\
(\mu F)\end{array}$} & \multirow{2}{*}{$\begin{array}{l}\Delta C \\
\text { mean } \\
(\mu F) \\
0.215\end{array}$} & \multirow{2}{*}{$\begin{array}{l}\begin{array}{l}\Delta C \\
\text { polyn. } \\
(\mu F)\end{array} \\
0.217\end{array}$} & \multirow{2}{*}{$\begin{array}{l}\begin{array}{l}\Delta C \\
\text { spline } \\
(\mu \mathrm{F})\end{array} \\
0.215\end{array}$} \\
\hline & 0.212 & 0.219 & 0.214 & 0.217 & & & \\
\hline 2.0 & 0.548 & 0.565 & 0.565 & 0.566 & 0.562 & 0.556 & 0.561 \\
\hline 3.0 & 0.873 & 0.861 & 0.876 & 0.885 & 0.874 & 0.878 & 0.873 \\
\hline 6.0 & 1.62 & 1.62 & 1.60 & 1.64 & 1.62 & 1.62 & 1.62 \\
\hline 8.0 & 1.93 & 1.94 & 1.94 & 1.93 & 1.93 & 1.94 & 1.93 \\
\hline 10.0 & 2.27 & 2.30 & 2.25 & 2.23 & 2.26 & 2.26 & 2.26 \\
\hline
\end{tabular}

TABLE 2

Flow injection determination of detergents

\begin{tabular}{|c|c|c|c|c|c|}
\hline \multirow[t]{2}{*}{ Compounds } & \multicolumn{3}{|c|}{ Concentration $\left(\times 10^{-5} \mathrm{M}\right)$} & \multicolumn{2}{|c|}{ Error (\%) } \\
\hline & Given & $\begin{array}{l}\text { Found } \\
\text { polyn. }\end{array}$ & $\begin{array}{l}\text { Found } \\
\text { spline }\end{array}$ & Polyn. & Spline \\
\hline Hyamine $1622^{\mathrm{a}}$ & 5.00 & 5.07 & 5.06 & +1.4 & +1.2 \\
\hline Hyamine $1622^{\mathrm{a}} \mathrm{b}$ & 5.00 & 4.90 & 4.93 & -2.0 & -1.4 \\
\hline Sodium dodecylsulphate & 50.0 & 50.0 & 50.4 & +1.0 & +0.8 \\
\hline Hyamine $10 \mathrm{X}^{\mathrm{a}}$ & 5.00 & 5.08 & 5.12 & +1.6 & +2.4 \\
\hline Benzalkonium chloride ${ }^{a} \mathrm{c}$ & 30.0 & 29.7 & 29.6 & -1.0 & -1.3 \\
\hline Dioctyl sodium sulfosuccinate ${ }^{a}$ & 5.00 & 5.20 & 5.20 & +4.0 & +4.0 \\
\hline Hexadecyltrime thylammonium Bromide & 5.00 & 4.90 & 4.90 & -2.0 & -2.0 \\
\hline Triton $\mathrm{X}-100^{\mathrm{c}}$ & 25.5 & 24.5 & 24.4 & -3.9 & -4.3 \\
\hline Hexadecylpyridinium chloride & 5.00 & irreversil & ble adsorp & tion & \\
\hline
\end{tabular}

${ }^{a} 5 \times 10^{-6} \mathrm{M}$ detergent in supporting electrolyte. ${ }^{b}$ Independent calibration. ${ }^{c}$ Concentration in $\mathrm{mg} \mathrm{l}^{-1}$. 
no significant difference is observed between the values calculated on the base of the polynomial or cubic spline function. The accuracy of the method appears to be about $\pm 4 \%$. In the case of hexadecylpyridinium chloride, the adsorption is irreversible and no return to the baseline occurs even after prolonged waiting times. In such cases, the electrode surface has to be wiped with a tissue and the electrode dipped in mercury again before use for the next sample.

The present flow injection procedure allows the determination of at least 60 samples $\mathrm{h}^{-1}$. As for all tensammetric procedures, it is not possible to differentiate between different kinds of surfactants. Because of this lack of selectivity, the proposed method is only suitable for well-defined samples as is generally the case with, for example, process streams.

The authors thank $W$. Lengton for carrying out preliminary experiments, Mrs. B. Verbeeten-Van Hettema for preparing the manuscript and R. H. Arends for making the drawings.

\section{REFERENCES}

$1 \mathrm{H}$. Konig, Neuere Methoden zur Analyse von Tensiden, Springer-Verlag, Berlin, 1971.

2 K. Vytras, M. Remes and H. Kubesova-Svoboda, Anal. Chim. Acta, 124 (1981) 91.

3 K. Vytras, M. Dajkova and V. Mach, Anal. Chim. Acta, 127 (1981) 165.

4 D. L. Jones, G. J. Moody, J. D. R. Thomas and B. J. Birch, Analyst, 106 (1981) 974.

5 M. Sak-Bosnar and M. S. Jovanovic, Mikrochim. Acta, (I) (1981) 409.

6 T. Kobayashi, M. Kataoka and T. Kambara, Talanta, 27 (1980) 253.

7 W. Selig, Fresenius Z. Anal. Chem., 300 (1980) 183.

8 N. Ciocan and D. F. Anghel, Fresenius Z. Anal. Chem., 290 (1978) 237.

9 S. G. Cutler, P. Meares and D. G. Hall, J. Electroanal. Chem., 85 (1977) 145.

10 M. Bos, Anal. Chim. Acta, 135 (1982) 249.

11 M. J. Rosen, X. Hua, P. Bratin and A. W. Cohen, Anal. Chem., 53 (1981) 232.

12 D. Britz, Anal. Chim. Acta, 115 (1980) 327.

13 D. R. Canterford and R. J. Taylor, J. Electroanal. Chem., 98 (1979) 25.

14 J. Lankelma and H. Poppe, J. Chrom. Sci., 14 (1976) 310.

15 H. Jehring, J. Electroanal. Chem., 20 (1969) 33.

16 J. Kawase and M. Yamanaka, Analyst, 104 (1979) 750.

17 K. W. Petts and I. Sliney, Water Res., 15 (1981) 129.

18 J. Kawase, A. Nakae and M. Yamanaka, Anal. Chem., 51 (1979) 1640.

19 J. Kawase, Anal. Chem., 52 (1980) 2124.

20 J. Koryta, Collect. Czech. Chem. Commun., 18 (1953) 206.

21 D. Britz and D. Knittel, Electrochim. Acta, 20 (1975) 891.

22 W. A. Halang, R. Langlais and E. Kugler, Anal. Chem., 50 (1978) 1829.

23 L. M. Schwartz, Anal. Chem., 49 (1977) 2062.

24 NAG FORTRAN Library Manual, Mark 9, Vol. 2, Numerical Algorithms Group Ltd., Oxford, 1981.

25 C. de Boor, A Practical Guide to Splines, Springer-Verlag, Berlin, 1978.

26 W. E. van der Linden and R. Oostervink, Anal. Chim. Acta, 101 (1978) 419. 